\title{
FERTILITY AND HATCHABILITY OF PEKIN AND MUSCOVY DUCK EGGS AND PERFORMANCE OF THEIR DUCKLINGS
}

\author{
M. A. Rashid1, M. H. Kawsar'2, M. A. Rashid ${ }^{3}$ and M. Y. Miah ${ }^{4}$ and \\ M. A. R. Howlider \\ Department of Poultry Science, Bangladesh Agricultural University \\ Mymensingh-2202, Bangladesh
}

\begin{abstract}
Five hundred ten duck eggs of Pekin and each of Muscovy duck eggs were incubated to determine fertility and hatchability. The eggs were cleaned and stored at $18-21^{\circ} \mathrm{C}$ for 6 days prior to setting in the incubator. The eggs were incubated in a forced-draft electric incubator and the hatching performances were recorded. Ninety Pekin and ninety Muscovy day-old ducklings were randomly selected from the hatched ducklings for a growth trial. Each breed was divided into three replications and each replication had 30 ducklings. They were reared up to 10 weeks of age. Fertility of Muscovy duck eggs tended to be higher $(P>0.05)$ than that of Pekin duck eggs. Hatchability of Pekin egg on fertile egg was higher $(\mathrm{P}<0.05)$ than that of Muscovy eggs. But, dead in shell of Muscovy duckling was higher $(\mathrm{P}<0.05)$ than that of Pekin duckling. Feed consumption was higher $(\mathrm{P}<0.01)$ in Muscovy ducklings than that of Pekin ducklings. Feed conversion was slightly higher $(\mathrm{P}>0.05)$ in Muscovy ducklings than that of Pekin. At 10 weeks of age, Muscovy ducklings were slightly heavier $(\mathrm{P}>0.05)$ than that of Pekin. It was concluded that the fertility of Pekin and Muscovy ducks are more or less similar while hatchability is higher in Pekin ducks. Muscovy ducks are superior in respect of feed conversion and growth rate.
\end{abstract}

Key words : Pekin, Muscovy, Duck egg, Fertility, Hatchability, Ducklings, Farm condition

\section{NTRODUCTION}

Bangladesh is a riverine country and $16488 \mathrm{~km}^{2}$ area are haors, baors, canals, ponds and low lying water reservoirs (Asian Livestock, 1988), part of which can be efficiently utilized for duck production. Ducks are not competitors of chicken because their scavenging venue is different. Therefore, increased duck rearing does not necessary mean a cut in chicken production. Rather, it will be a great supplement to total poultry production. Duck ranked second place in supplying egg and meat and are traditionally reared under semi-scavenging system in Bangladesh. Ducks are considerably cheaper to raise and more resistant to diseases than that of chicken.

\footnotetext{
${ }^{1}$ Manager, Northern Hatchery, Bagura, Bangladesh

2 Assistant Professor, Department of Dairy and Poultry Science, PSTU, Bangladesh

3 Assistant Professor, Department of Animal Science and Nutrition, PSTU, Bangladesh

4 Assistant Professor, Department of Dairy and Poultry Science, SAU, Bangladesh
} 
Ducks are efficient converter of insects, weeds and fallen seeds into meat and eggs (NRC, 1994). In some areas of Bangladesh, farmers prefer to rear ducks instead of chicken. For multiplication of duck, fertility and hatchability are the most important contributing factors to take care of.

Fertility and hatchability are influenced by genetic background, physiology, nutrition and social behavior and environment (Warren, 1953; Olsen and Hyne, 1948; Hut, 1938; and Jull, 1970). Therefore, it is imperative to identify the best breed in terms of fertility and hatchability of eggs and their growth performance. In this experiment, the prolificacy and growth performance of Pekin and Muscovy ducks were compared.

\section{MATERIALS AND METHODS}

\section{Experiment 1, reproductive parameters}

A total 1020 hatching eggs; 510 of Pekin and 510 of Muscovy were properly cleaned in mild lukewarm diluted solution of anti-septic and stored at $18-21^{\circ} \mathrm{C}$ for 6 days before setting in a forced-draft electric incubator. After setting eggs, the machine was thoroughly fumigated by potassium permanganate and formaldehyde method as per recommendation of the incubator manufacturer. The candling of eggs was done at $10^{\text {th }}$ and $24^{\text {th }}$ days of incubation with the help of an electric candler to sort out the clean eggs and dead embryos. At $10^{\text {th }}$ day of incubation in each hatch, the clean eggs as examined by candling were recorded as infertile eggs. The eggs with developed germinal disc were considered as fertile. Fertility percent of eggs was calculated as total number of fertile eggs divided by total number of eggs set multiplied by 100 .

At the end of hatch, the hatched eggs showing stickiness and pips were counted separately as dead-in-shell. At $24^{\text {th }}$ day of incubation, the eggs were further candled by an electric candler. The embryo of hatching eggs showing the evidence of retarded development on candling were considered as dead embryos, which were subsequently confirmed by the broken out examination. The ducklings that showed defect in structure, size, shape, feathering and other abnormalities like lameness, blindness and open navels were recorded and considered as abnormal ducklings.

\section{Experiment 2, growth trial with Pekin and Muscovy ducks}

Ninety Pekin and ninety Muscovy day old as hatched ducklings were selected for this study. Each breed had three replications having 30 ducklings in each replication.

The ducklings belonging to two genotypes were brooded for a period of 3 weeks on a wire net floor. The experiment was conducted during November to January and house temperature was maintained by increased and reduced intensity of electric bulb. After 3 weeks of brooding, the ducklings were transferred to growing house and reared separately in 6 pens. Fresh and well dried sand was used as a litter in each pen at a depth of $8 \mathrm{~cm}$ and $0.23 \mathrm{~m}^{2} /$ bird floor space was provided to each duckling during the growing period. Temperature and relative humidity were recorded three times in a day. Two 
experimental diets (starter and grower) were formulated with locally available feed ingredients. Feed and water were supplied ad-libitum through out the experiment. Feeder and water spaces were considered according to the number and age of the ducklings in each replication. A starter diet containing $2911.80 \mathrm{kcal} / \mathrm{kg} \mathrm{ME}, 21.55 \% \mathrm{CP}, 1.16 \% \mathrm{Ca}$, $0.46 \%$ Av. P, $1.25 \%$ lysine, $0.51 \%$ methionine and $0.29 \%$ tryptophan was fed up to 3 weeks of age. A grower diet was fed from 4 to 10 weeks of age which contained $2993.13 \mathrm{kcal} / \mathrm{kg}$ $\mathrm{ME}, 17.58 \% \mathrm{CP}, 0.95 \% \mathrm{Ca}, 0.39 \%$ Av. $\mathrm{P}, 1.03 \%$ lysine, $0.42 \%$ methionine and $0.25 \%$ tryptophan. All ducklings were vaccinated against Duck Plague disease as per recommendation of the vaccine manufacturer.

Records of initial live weight, feed intake and dead birds were kept replication-wise. The feed conversion ratio ( $\mathrm{g}$ feed/g weight gain) and mortality were calculated. The experimental data were analyzed statistically using analysis of variance (ANOVA) technique for Completely Randomized Design (CRD) and statistical significances were recorded.

\section{RESULTS AND DISCUSSION}

\section{Hatching performance}

Embryonic mortality and abnormal ducklings were slightly higher $(\mathrm{P}>0.05)$ in Pekin than those in Muscovy (Table 1). Whereas, fertility, dead in shell and normal ducklings tended to be higher in Muscovy than that in Pekin. Higher $(\mathrm{P}<0.05)$ hatchability on fertile eggs was observed in Pekin in comparison with that of Muscovy.

Table 1. Hatching performance of Pekin and Muscovy duck eggs

\begin{tabular}{l|c|c|c|c}
\hline \multicolumn{1}{c|}{ Variables } & Pekin & Muscovy & SED values & $\begin{array}{c}\text { Level of } \\
\text { significance+ }\end{array}$ \\
\hline Fertility (\%) & 80.96 & 86.69 & 1.978 & NS \\
Hatchability on fertile eggs (\%) & $62.91^{\mathrm{a}}$ & $54.21^{\mathrm{b}}$ & 8.331 & $*$ \\
Embryonic mortality (\%) & 9.14 & 5.12 & 4.630 & NS \\
Dead-in-shell (\%) & 27.96 & 40.68 & 6.541 & NS \\
Abnormal ducklings hatched (\%) & 3.99 & 2.78 & 0.956 & NS \\
Normal ducklings hatched (\%) & 96.01 & 97.22 & 0.956 & NS \\
\hline
\end{tabular}

All SED's are against 4 error degrees of freedom; Values with dissimilar superscripts in a raw are significantly different $\mathrm{P}>0.05 ;{ }^{*} \mathrm{P}<0.05(+\mathrm{NS})$

Increased hatchability of fertile eggs recorded for Pekin egg $(\mathrm{P}<0.05)$ than that of Muscovy eggs. Such a difference in fertility and hatchability between breeds obtained study with previous finding $(22.7 \%)$ might have been arisen for genetic $\times$ environment interaction. Ali et al. (1989) found much lower hatchability $(22.7 \%)$ in Muscovy eggs. Environmental factor (e.g. temperature, humidity, turning etc.) might be causes of higher dead in shell. However normal ducklings hatched out from Muscovy was little higher than that of Pekin Ducklings $(\mathrm{P}>0.05)$. 


\section{Growth performance}

Initial live weight of Pekin ducklings and Muscovy ducklings were $47.05 \mathrm{~g}$ and $46.39 \mathrm{~g}$ respectively. It was observed from Fig. 1 that live weight up to 6 weeks of age was similar but from 6 to 10 weeks of age Muscovy grew faster than that of Pekin. Begot and Karunajecwa (1976) and Hagel (1983) reported that Pekin grew faster than that of Muscovy at 3 week of age, but from 3 to 9 weeks of age, growth rate was similar in two genotypes.

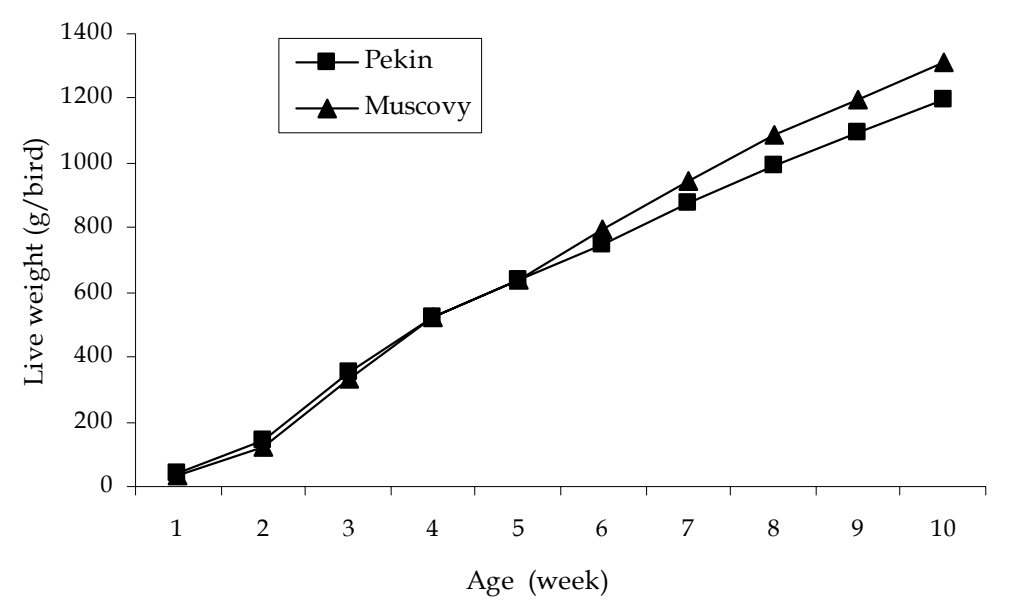

Fig. 1. Live weight of Pekin and Muscovy

Feed consumption regardless of age were almost similar $(\mathrm{P}>0.05)$ in Muscovy and Pekin (Fig. 2) but comparatively higher feed intake was observed in Pekin than that of Muscovy.

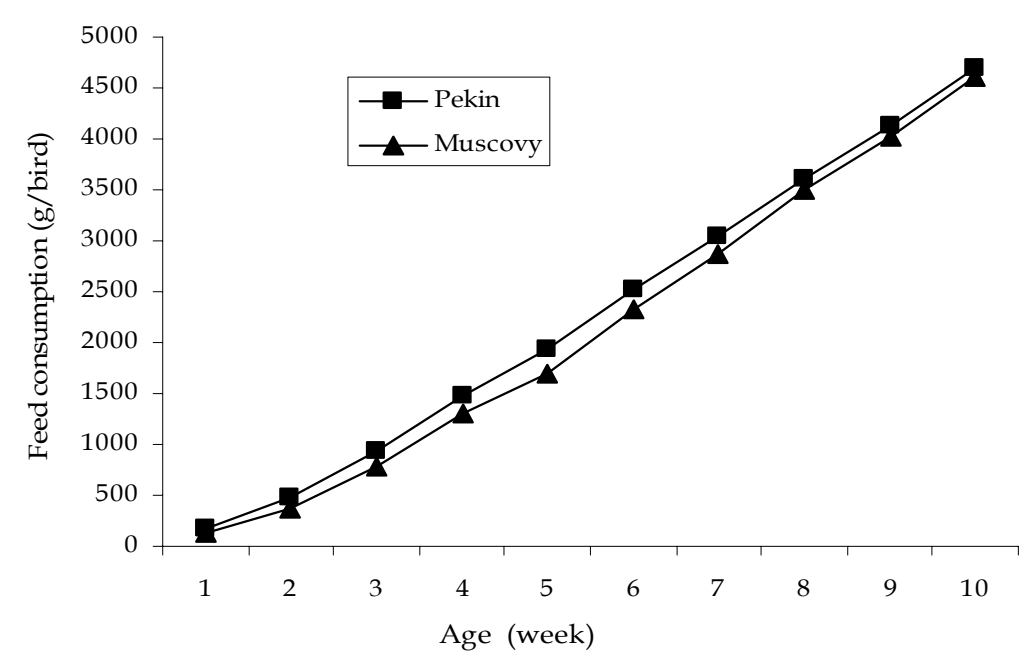

Fig. 2. Feed consumption of Pekin and Muscovy 
In Fig. 3, a trend of lower feed intake and inferior feed conversion in Muscovy than that in Pekin may have been arisen for slower early weight of Muscovy compared to their Pekin counterparts. Feed efficiency was always higher $(\mathrm{P}>0.05)$ in Pekin ducklings but significantly higher $(\mathrm{P}<0.01)$ at $4^{\text {th }}$ and $5^{\text {th }}$ week of age in comparison with of Muscovy ducklings. The results are also in agreement with the findings of Chom-Boonchan (1987), Oliver et al. (1987); Pingel and Jeroch (1969).

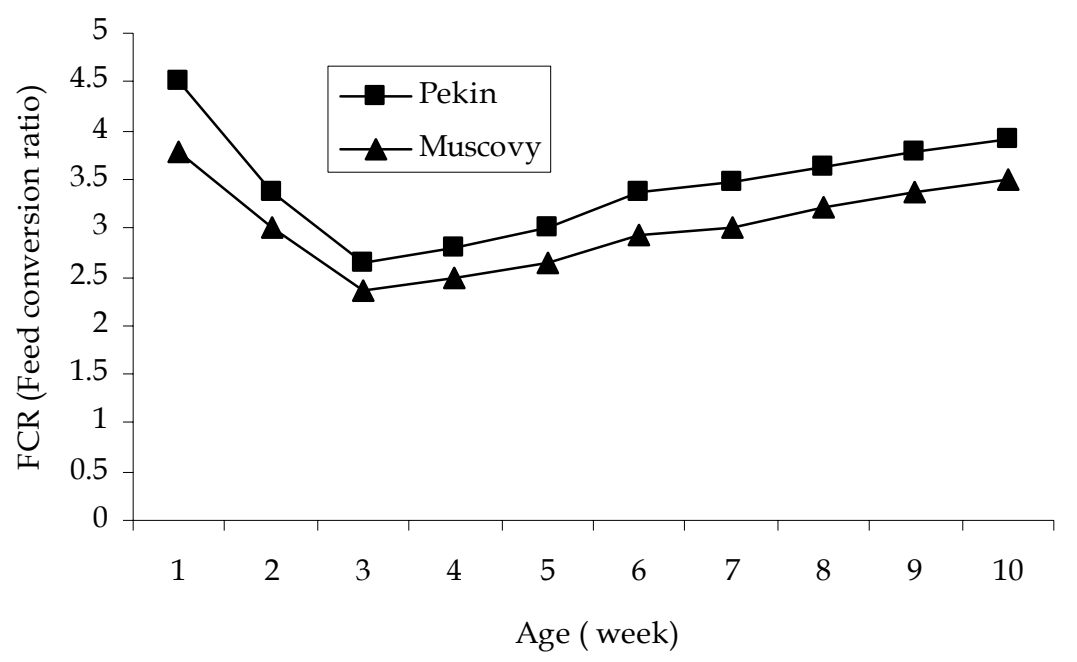

Fig. 3. Feed conversion efficiency of Pekin and Muscovy

From the results of this study, it was concluded that the fertility of Pekin and Muscovy ducks are more or less similar while hatchability is higher in Pekin ducks. Muscovy ducks are superior in respect of feed conversion and growth rate.

\section{REFERENCES}

Aggarwal, C. K. and Dipanlar, K. 1989. Effect of male-female ratio on fertility of white Pekin ducks. Indian J. Anim. Prod. Manage., 2(4): 193-194.

Ali, M. A., Rahaman, M. A., Wahid, M. A. and Singh, T. K. 1989. The hatchability of Muscovy duck eggs under natural and artificial incubation. Bangladesh J. Anim. Sci., 8(1): 13.

Ahmed, S. and Islam, N. 1990. Backyard Poultry Development Project in 100 Villages. Proceeding of the first conference of Bangladesh Animal Husbandry Association. Feb. 23-24, 1985. Bangladesh Agricultural Council, Dhaka, Bangladesh.

Assian Livestock. 1988. FAO. Regional Animal Production and Health Commission for Asia and the Pacific (APHCA). 10(4): 6.

Bagot, I. and Karunajecwa, H. 1976. Effect of diet on growth and carcass characteristics of duck meat production. Anim. Breed. Abst., 47(4): 423.

Chome-Boonchan. 1978. Study of comparative production of meat type ducks in Thailand. Anim. Breed. Abst., 55(7): 289. 
Das, S. K. 1994. Poultry Production, CBS Publishers and Distributors. 485 Bholanath Nagar, Delhi-110032 (India): 203-211.

Hetzel, D. J. A. 1983. A note on the differences in growth tissue deposition of crosses between Pekin and Muscovy drakes and alabio ducks. Poult. Abst., 9(4): 48.

Hutt, F. B. 1938. The Geneticists objectives in Poultry improvement. American Naturalists. 72: 268.

Jull, M. A. 1970. Considerable progress achieved in breeding for increased egg production in Egypt. World Poult. Sci. J., 26: 200-202.

Oliver, M. D., Preez, Z. I., Dual Kuyper, M. A. and Moulds, D. J. 1987. The carcass composition and growth of the "mule ducklings" compared to purebred ducklings. Poult. Abst., 4(5): 72.

Pingel, H. and Jeroch, H. 1969. Investigation on fattening and carcass performance as well as meat quality of Muscovy drake x Pekin duck crossbred. Anim. Breed. Abst., 0(3): 578.

Sogomonov, A. and Rakhamanov, L. 1988. The production of Muscovy ducks in hot climate. Poult. Abst., 14(7): 215. 